\title{
Preface
}

\section{Simon W. Bowmaker}

This book applies microeconomics to social issues. From drugs to divorce, pornography to prostitution, sport to suicide, and religion to rock 'n' roll, we show that economics can reach into the strangest of places and shed light onto the occasionally dark side of human nature. Most importantly, we establish that with every issue of society the economist has a right to speak, and can do so usefully.

The idea to put together this book originated at the University of Edinburgh, where I first taught in 1999. I quickly discovered that students have a surprisingly healthy appetite for a diet of sex, drugs and economics. My experiences in the United States, including spells lecturing at Florida State University and the State University of New York, Buffalo, convinced me that they (and their instructors) would appreciate such a volume. However, I am also aware from discussions with wider social contacts that people are interested in the issues we cover, but are still in search of an analytical framework for clarifying their opinions and decision-making. The chapters that follow will be of great value to these individuals.

To motivate the various topics, our starting point is a conversation with Gary Becker, the economist who has pioneered the application of microeconomics to whole areas of life that conventional wisdom may deem either inappropriate or inaccessible. I sought his views on a broad range of contemporary social issues, including drug legalization, same-sex marriage, capital punishment and suicide bombing.

We then proceed as follows. Part I, 'Sins and Needles', is a three-chapter examination of illicit drug use and policy. In Chapter 1, Frank Heiland and I analyse theories of addictive behaviour, the price elasticity of demand for illicit drugs, and the welfare economics of drug prohibition. Next, in Chapter 2, Jeffrey Miron shows that the unusual features of drugs markets result from their legal status, not from the mind-altering and addictive properties of drugs themselves. Finally, in Chapter 3, Mark Thornton, Bruce Benson and I examine the economics of drug liberalization, including the alternative policies of government monopoly, regulation, sin taxes and the free market.

Part II, 'Guns and Roses', looks at the contribution economists can make to understanding crime and marriage and divorce. In Chapter 4, Bruce Benson and I investigate the economic theory of the supply of 
criminal offences, the demand for crime prevention and law enforcement services, the allocation of resources within the criminal justice system and the possible reasons for the decline in crime rates in the USA in the 1990s. In Chapter 5, Leora Friedberg and Steven Stern then examine the gains from marriage versus living together and develop an economic model to help explain why people marry, the nature of decision-making within marriage and the nature of the decisions to marry and to divorce.

Part III, 'Body and Soul', begins with two chapters on the economics of sex. In Chapter 6, Samuel Cameron looks at research outcomes on the effects of pornography, the characteristics of the industry, Amartya Sen's argument about Paretian liberals as applied to porn, the nature of demand for porn, government approaches to its regulation, the impact of the Internet and the positive externalities arising from the consumption and production of porn. Next, in Chapter 7, Peter Moffatt considers the economics of prostitution. He examines theoretical models that seek to explain, among other things, how equilibrium earnings are so high in a profession with only rudimentary skill and capital requirements, analyses the empirical evidence relating to prostitution and discusses the issue from a policy perspective, including a description and evaluation of various models of legalization. In Chapter 8, Samuel Cameron turns to the economics of suicide. He discusses Emile Durkheim's socio-economic contribution to the subject, examines economic models of suicide and the empirical work undertaken by economists, investigates the potential economic cost of suicides, including those of celebrities, and shows how an anti-suicide bureau might operate. Finally, in Chapter 9, Robert Stonebraker examines the economics of religion. He considers the demand for religion, supply-side issues such as how providers of religious goods and services cope with free-riders, the problems of risk and uncertainty in religious choice and how competition and government regulation shape the structure and content of religious markets.

Part IV, 'Conception and Rejection', focuses upon the controversial economics of assisted reproduction and abortion. In Chapter 10, Sherrie Kossoudji provides an introduction to the markets for assisted reproduction, discusses the economics of the demand and supply of children, explores the development and size of markets in assisted reproduction, examines the economic issues in the markets for eggs, sperm and surrogacy, and undertakes a discussion of the ethics of assisted reproduction markets. Next, in Chapter 11, Leo Kahane looks at the demand and supply of abortion services and demonstrates how these fundamental tools of economic analysis can be used to understand the workings of the market. He reveals how the availability of abortion services and their legality has had ramifications for other related issues such as teen pregnancy rates, the 
propensity for pre-marital relations and fluctuations in crime rates across time.

Finally, Part V, 'Fun and Games', examines the economics of sport, gambling and music. In Chapter 12, John Goddard and Peter Sloane consider the objectives followed by team and league owners in sport, investigate the nature of product demand, the sports league's role as a cartel and issues relating to the efficacy and desirability of revenue-sharing, salary caps and collective selling of broadcasting rights. In Chapter 13, Robert Simmons examines the fundamental economic question of why people gamble and considers the economic reasons why US states and governments across the world may opt to legalize forms of gambling. He also looks at some contemporary policy issues involved in regulation and deregulation of gambling, including the social benefits and costs, the use of state government revenues from gambling for particular purposes and the threat to government tax revenues and government regulation posed by the growth of Internet gambling. In Chapter 14, Ronnie Phillips, Richard Johnson and I provide a brief history of the music industry, examine the complex relationships between the major record companies and the independents, and analyse the economics of recording contracts. We also show how technological change is affecting the relationship between record label and artist, investigate the presence of the 'superstar phenomenon' in music and discuss the economics of copying music.

So, various dimensions of social behaviour and interaction are discussed in every chapter, but this has only been possible because extensive use is made of economic analysis. Indeed, long-standing economics concepts are shown to have continued potency throughout. Marginal utility and price elasticity of demand are crucial to the analysis of illicit drug addiction. Traditional demand and supply analysis still has a lot to offer to the criminologist and to the student of abortion. Old and new economic theories jostle to provide a framework for analysis. The sturdy theory of the firm is useful in examining sport, prostitution and rock 'n' roll, while game theory helps the analysis of suicide and marriage and divorce.

Of course, inevitably linked to the presentation of a social problem is consideration of a policy response. Some of the issues discussed come into conflict with the criminal law, for example, sale of particular drugs, so the economics of enforcement and prohibition are given weighty consideration. Long-established policies such as competition policy have relevance in fields such as sport. Taxation policy is used to examine the economics of drug liberalization, and a variety of forms of regulation are dissected, even in unusual matters such as religion. First and foremost, this is a book about economics. 